\title{
Study of a non-conventional sealing system for low-friction pneumatic cylinders
}

\author{
T. Raparelli, L. Mazza \& A. Trivella \\ Department of Mechanical and Aerospace Engineering, \\ Turin Polytechnic, Italy
}

\begin{abstract}
This paper investigates a new sealing system for sliding applications in pneumatic cylinders based on non-contact sealing. By "reverse" assembling the common lip seal, the back of the seal is exposed to the supply pressure and the lip is turned towards the pressure discharge side. When exposed to sealing pressure the lip yields, resulting in reduced effective surface area with consequent less friction and wear, providing an air leakage path the flow rate of which depends on the radial stiffness of the seal. The aim of this work is to develop a methodology for evaluating the performance of a non-conventional seal system design (air lubricated seal). A spring-energised commercial seal fitted to a piston has been tested to measure the air flow rate through it. More specifically, to evaluate the extent of the influence of cylinder bore diameter and machining tolerance. Preliminary results are presented and discussed.

A major factor was to avoid, or at least reduce, frictional problems by using a non-conventional common lip seal assembly solution.

Keywords: seals, sealing systems, pneumatics.
\end{abstract}

\section{Introduction}

Sliding seals are a crucial component of linear pneumatic actuators. The seal must provide pressurised fluid sealing across front and rear chambers and across front chamber and the atmosphere. Contact implies friction, with resulting energy dissipation and component wear. Thus, actuator performance is influenced in terms of actual thrust, stroking speed rate and smoothing of actuation. With conventional seals friction increases with fluid pressure as, to ensure effective sealing the seals are energised by the sealing pressure itself. 
The design and development of sliding seals, as well as tribological performance in terms of friction, wear and sealing efficiency involve multiple branches of science and engineering, namely structural calculations for stressstrain analysis and for studying new low-friction geometries [1-3], material science to define new materials [4], surface mechanics to study new surface geometry of part and counterpart with low-friction and high wear resistance (texturing, coatings, etc.) [5-8], and contact tribology [9-14]. In addition to the above concerning the seal as such, much work has been done on evaluating the performance of seals installed on final components, typically actuators, through experimental analysis to assess seal durability and efficiency on actuators under radial load [15, 16], as well as on developing methodologies for evaluating friction $[17,18]$.

To offset or eliminate altogether the limits imposed by sliding-contact seals, the literature offers innovative solutions of seal-less, very low friction pneumatic cylinders. In particular, two different solutions are proposed. The first involves doing without seals and replacing them with pneumo-static support of piston and rod $[19,20]$, The second proposes using unconventionally assembled conventional lip seals $[21,22]$. In both cases sealing between surfaces in relative motion is no longer totally assured, a slight leakage being envisaged. The former solution is costly as metal-to-metal gaps call for close tolerances, whereas the latter is cost-effective thanks to the possibility of using unconventionally assembled commercial seals. Feasibility tests [21] of this new type of sealing carried out on a prototype and on a commercial seal installed on a commercial cylinder, permitted the evaluation of performance in terms of leakage and friction, ignoring the effects of seat geometry changes and bore manufacturing tolerances.

This research covers an experimental work to evaluate the effect of radial precompression on assembly, with changes in bore diameter and seal seat diameter. Performance is assessed in terms of leakage for a non-conventional seal solution. The resulting data will also be used to develop a mathematical model to be used in future design solutions.

\section{Non-conventional sealing system}

Figure 1 shows a section of the test device consisting of piston (1) and lip seal (2) unconventionally installed. Provision was made for the piston to accept either a single seal, as is the case of single-acting cylinders, or a double seal, typical of double-acting cylinders. Test results refer to the single seal application. Contrary to the conventional solution with the seal's lip facing towards the pressure side P1 acting on it for contact with bore (3), here the assembly is "reversed", i.e. the lip faces in the direction of breaking the contact under pressure $P_{l}$. Seal deformability must provide a narrow gap, i.e. non contact between lip and bore, the extent of leakage being sufficiently small so as to reduce friction without excessive loss of air. Stiffness is obtained by applying a load to the seal through metal spring (4). 


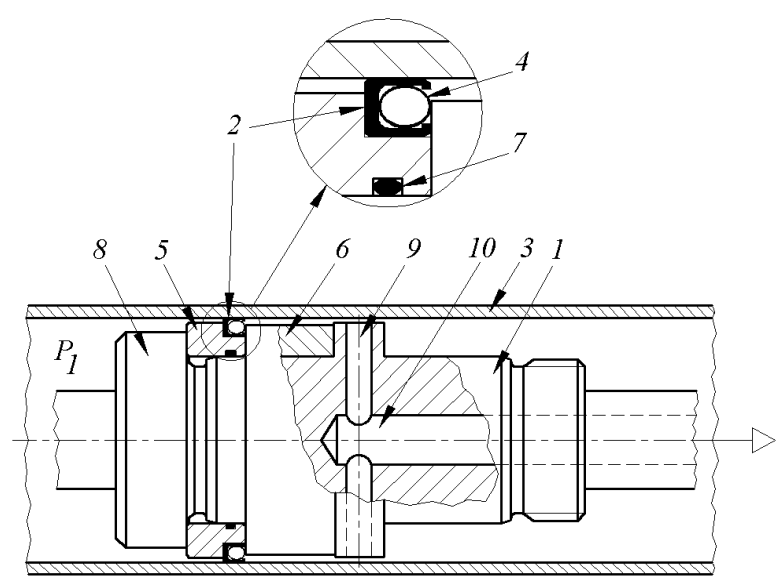

Figure 1: $\quad$ Test piston and seal, non-conventional assembly.

The seal is housed in a rectangular seat delimited by rings (5) and (6), which are easily replaced to permit inserting seals of various shapes and sizes within given dimensional limits. Ring (5) is suitable for the insertion of O-ring (7,) on its inside diameter, to prevent air leakage between ring (5) and piston (1), thereby allowing pressurised fluid to flow downstream only through seal (2) under test. Rings (5) and (6) are locked endwise by ringnut (8). Air flow through the seal is taken externally through four radial holes (9) and axial port (10) machined in piston and rod. Provision has been made for the holes to allow dual seal piston testing.

\section{Experimental set-up}

Figure 2 shows the test set-up for leakage test. Piston with test seal is installed inside pneumatic cylinder (1).

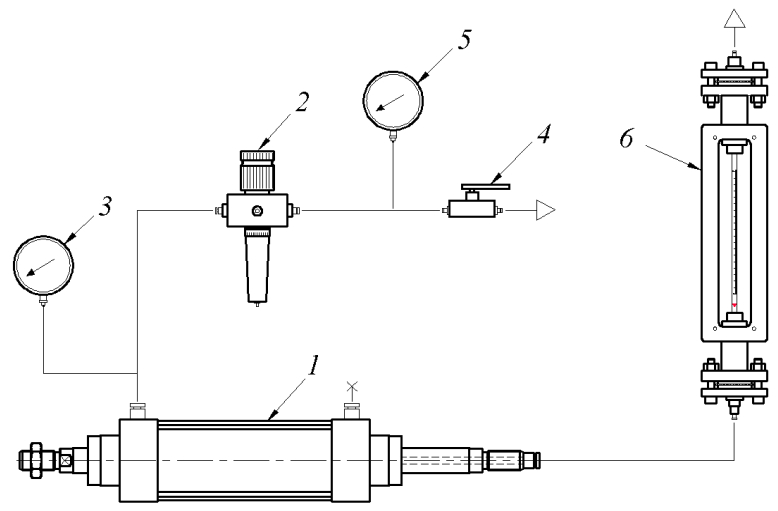

Figure 2: $\quad$ Test set-up schematics. 
The left chamber is connected to supply and the right chamber is plugged. Pressure is controlled through reducer (2) and pressure monitoring is by pressure gauge (3). The circuit also includes shut-off valve (4) and line pressure gauge (5). Leakage across the test seal via an axial port within the piston-and-rod group is measured by float-type flowmeter (6).

Testing consists in recording leakage at increasing pressure in cylinder chamber, i.e. upstream of the seal.

\section{Test conditions and test results}

Testing was carried out using commercial type seals by Bal Seal model 305 (424) G, for pistons, seal material being graphite-filled PTFE. Main dimensions of seal and housing are shown in Table 1. Nominal dimensions are taken from the manufacturer's catalogue; measured dimensions are obtained from two specimens.

Table 1: $\quad$ Test seals dimensions $(\mathrm{mm})$.

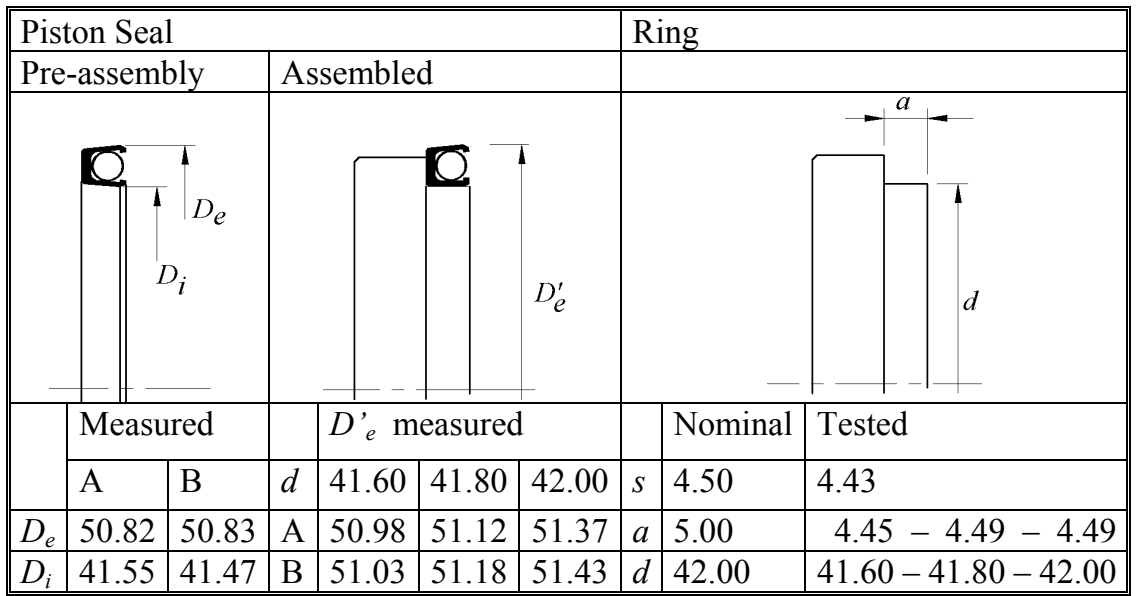

Leakage tests were carried out at 0 to 6 bar pressure in increasing increments on two seal specimens, A and B respectively, repeating each test at least three times for each sample. Three special calibrated cylinders, with bore diameter $\phi=50.0-50.1-50.2 \mathrm{~mm}$ respectively and inside surface roughness $\mathrm{Ra} \cong 0.6 \mu \mathrm{m}$, were used taking into account manufacturing tolerances which, for aluminium cylinder bores of pneumatic actuators are usually $t=0+0.2 \mathrm{~mm}$. Also the surface roughness is that of a commercial cylinder bore. Three assembly rings with diameter $d=41.6-41.8-42.0 \mathrm{~mm}$ were used, being $d=42.0 \mathrm{~mm}$ the nominal value (Table 1). In fact, cylinder and ring size determine seal radial precompression on assembly which has a direct influence on leakage flow rate.

Seat axial dimension $a$ found to be critical during testing, was changed from the initial nominal adopted for a set of preliminary tests to the final figures of 
Table 1. The manufacturers' nominal $a=5.00 \mathrm{~mm}$ is greater than seal's end width $s=4.50 \mathrm{~mm}$, thereby allowing for axial movement. As shown by tests, for nonconventional assembly endwise displacement does not define a univocal behaviour of the seal in terms of leakage: it may well happen that the seal leakage is either very high or nil, implying low repeatability. This is associated with marked seal movement, possibly leading to lip blockage with full obstruction of the gap even with increasing pressure. To prevent this, the seat end width was reduced to slightly in excess $(\sim 0.02-0.06 \mathrm{~mm})$ of the seal axial width, thereby ensuring greatly reduced axial movement. Axial lockup of rings (5) and (6), which delimit the seat (Figure 2), is ensured by the contact between rings without introducing tightening loads on the seal.

Figure 3 shows the trend of leakage with increasing pressure for specimen A. Two different seal assembly configurations are considered, namely $\phi 50.0-d 42.0 \mathrm{~mm}$ and $\phi 50.2-d 41.6 \mathrm{~mm}$, corresponding to max. and min. test assembly pre-compression respectively. The former is for nominal precompression conditions on assembly applicable to the seal in conventional condition. The chart shows increased leakage with increasing pressure and decreasing pre-compression on assembly.

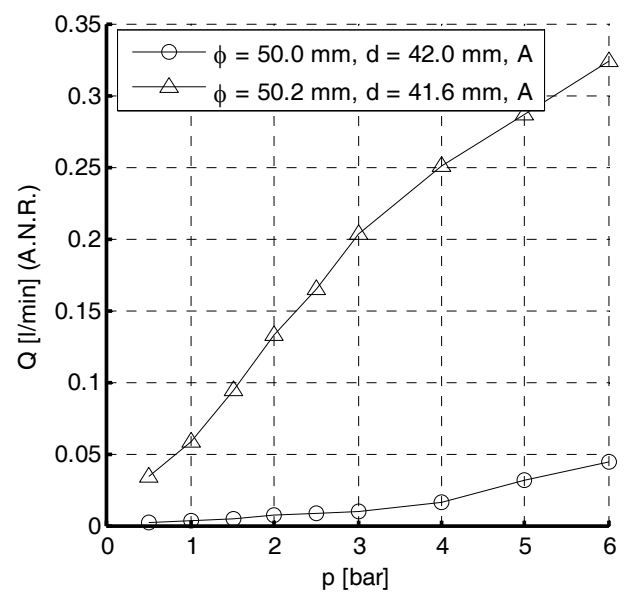

Figure 3: Leakage under minimum and maximum pre-load (specimen A).

Figure 4 shows the pattern of leakage for seal type B, with changing cylinder bore diameter and assembly ring diameter. For a given ring diameter leakage increases with increasing bore diameter $\phi$ and, vice versa, for a given bore diameter, leakage decreases with increasing ring diameter $d$. Geometric parameters influence leakage differently. In fact, changes in leakage are more marked with changing bore diameter $\phi$. With increasing ring diameter $d$ from 41.6 to $41.8 \mathrm{~mm}$ changes in leakage are less marked than with increasing ring diameter from 41.8 to $42.0 \mathrm{~mm}$. 

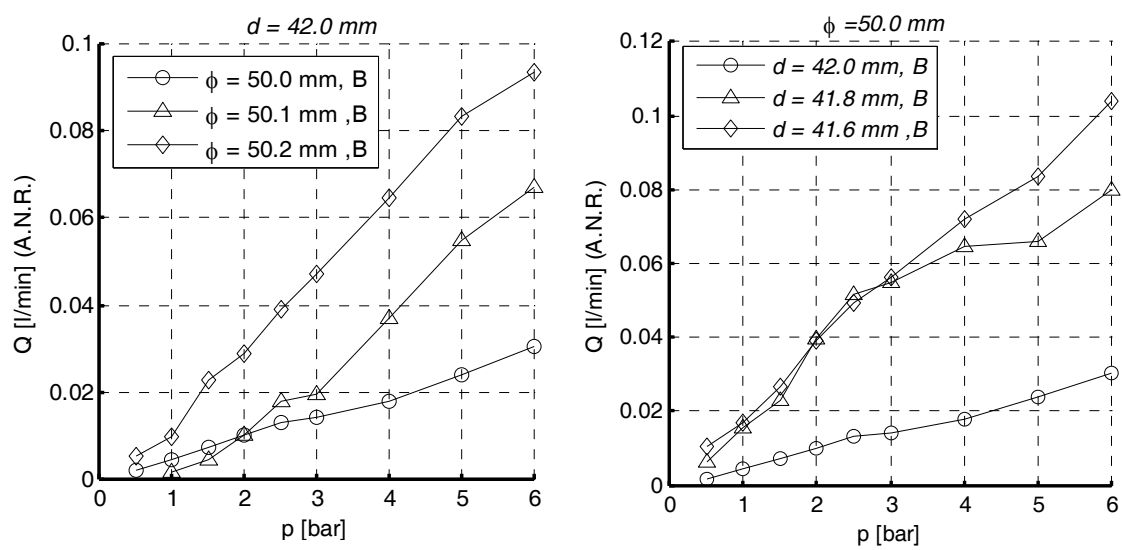

Figure 4: Incidence of leakage for various assembly conditions, specimen B.

Figure 5 shows by way of example the behaviour of specimens A and B tested to highlight leakage variability for different specimens. Due to the small number of specimens tested, the comparison is not meant to provide statistical evidence, the aim being to show how leakage is seal size-sensitive and is particularly influenced by the outside diameter.

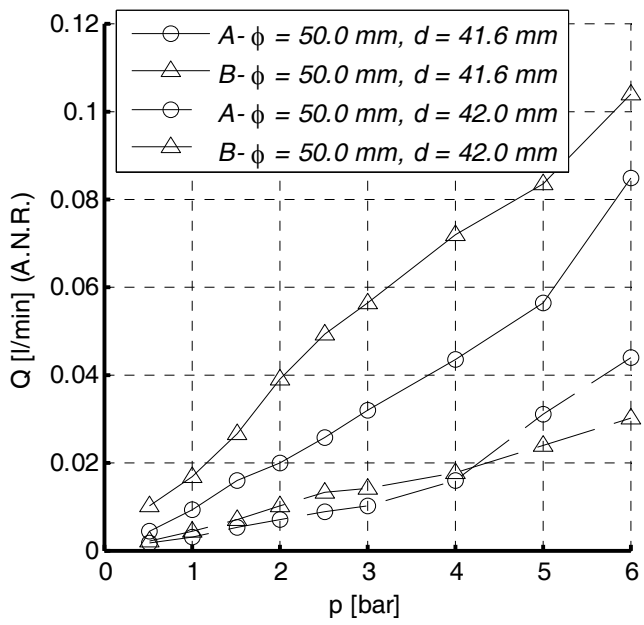

Figure 5: Comparison of leakage for the two tested specimens.

Figure 6 shows the effect of time on leakage readings The chart plots max. leakage at 6 bar, for successive tests with cylinder assembled. Leakage at 0 hours, Figure 6, was read immediately after seal installation on test device. Subsequent readings were taken at specified time intervals with seal installed on test device. With seal assembled in max. radial compression condition $(\phi 50.0-d 42.0 \mathrm{~mm})$, there was a marked reduction in leakage and a tendency 
to bed in. With diminishing pre-compression on assembly, leak-through was little influenced by the time on which the seal is installed on test device (see case $\phi 50.2-d 41.6 \mathrm{~mm})$. This denotes behaviour associated with a recovery of radial gap and settling of the seal relative to cylinder bore.

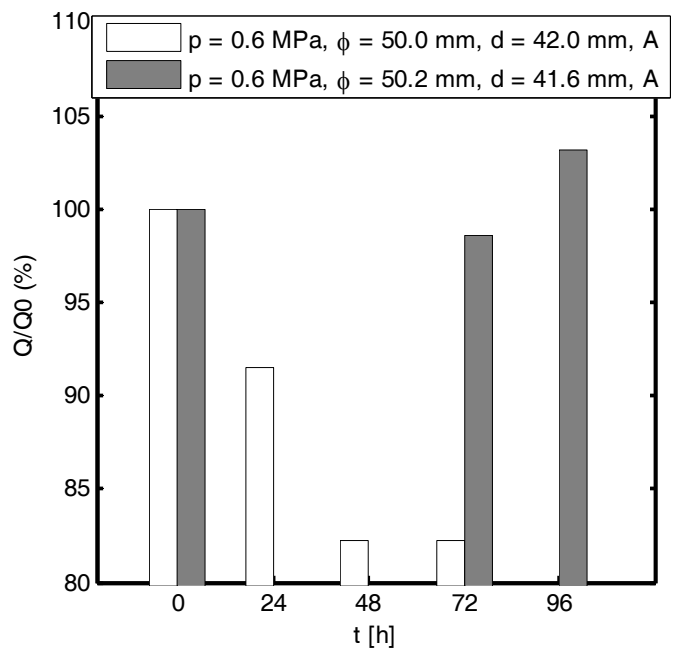

Figure 6: Incidence of leakage versus time (seal installed).

Figure 7 shows the trend of leakage at 6 bar in the different seal assembly conditions, i.e. versus cylinder bore diameter $\phi$ and ring diameter $d$. Results are average readings for test specimens $\mathrm{A}$ and $\mathrm{B}$. Changes are more marked with the

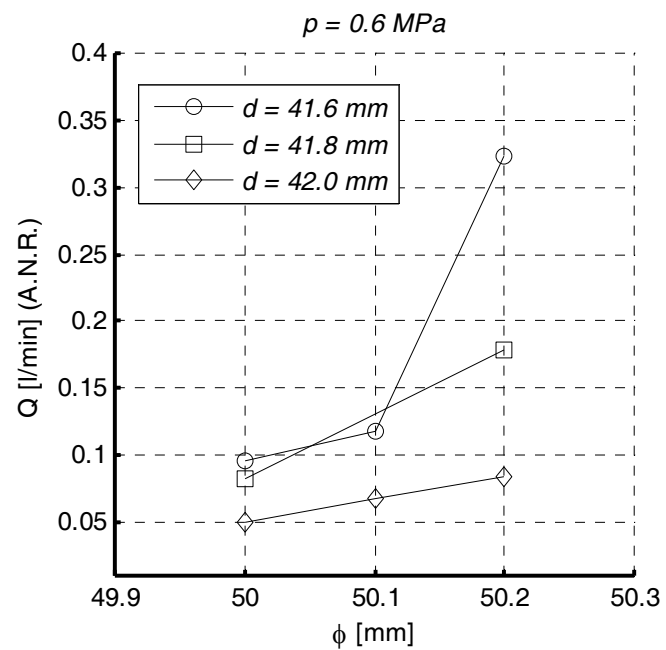

Figure 7: Incidence of leakage for the various assembly conditions. 
smaller diameter ring, whereas for the larger diameters $d$, with which precompression on assembly is greater, leakage is less sensitive to changes in cylinder bore diameter.

Figure 8 shows changes in seal outside diameter $D_{e}^{\prime}$ versus ring inside diameter $d$, with the amount of interference $\varepsilon=D_{e}^{\prime}-\phi$ of seal outside diameter relative to cylinder bore diameter. Interference increases with increasing ring diameter $d$. Conversely, parameter $\delta$ represents the difference in diameter $D^{\prime}{ }_{e}$ before and after the leakage test. Following compression on assembly, the seal does not recover immediately from deformation, returning to its original dimension after a rest period of at least $24 \mathrm{~h}$.
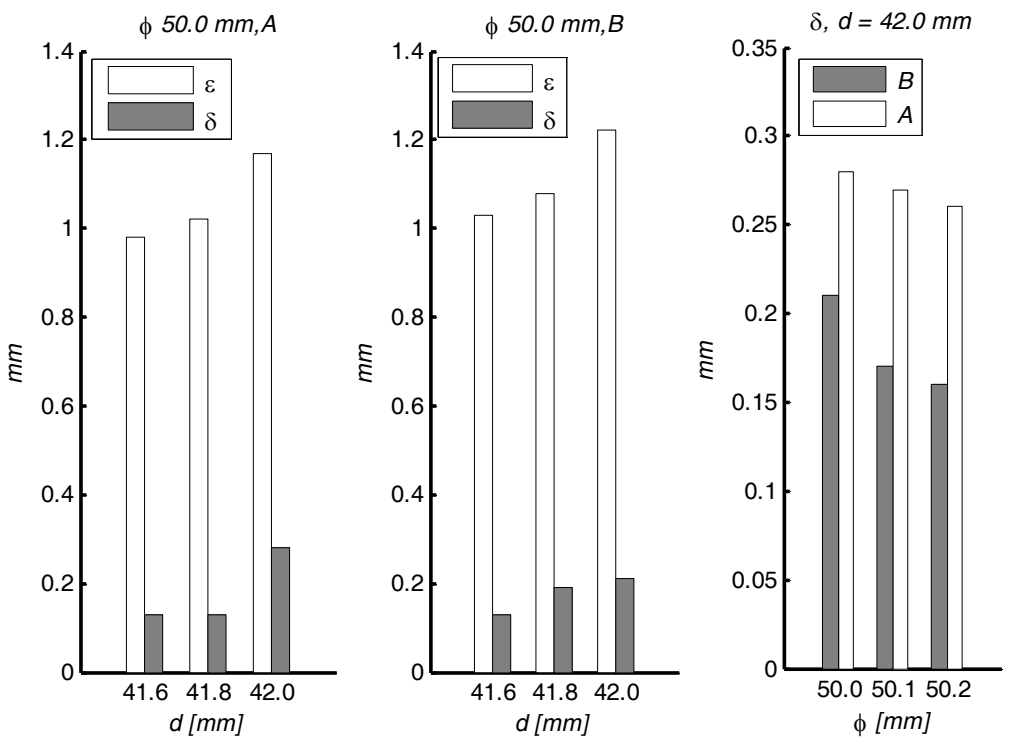

Figure 8: $\quad$ Fitted interference, change in outside diameter $D_{e}$ before and after test.

\section{Conclusions}

The initial tests were carried out to assess the performance of a non-conventional seal with changing fitted interference and cylinder bore diameter. Tests confirmed the effectiveness of the sealing system with a small amount of leakage and close to the limits imposed by standards for conventional seals. Thus, the configuration under investigation is suitable for cost-effective, low-friction, continuous positioning systems. Collated data will be used to identify a mathematical model for designing these types of sealing components. The development of suitable models will be a challenging proposition, as results obtained so far point to a viscous state with relaxation in time. Data currently available show a need for investigating other seals featuring elastic elements of 
lower stiffness, as in all probability the gap originates from seal material deformation rather than spring deformation.

\section{References}

[1] Calvert, C., Tirovic, M., and Stolarski, T., Design and Development of an Elastomer-Based Pneumatic Seal Using Finite Element Analysis, Journal of Engineering Tribology, 216 (J3), pp. 127-138, 2002.

[2] Belforte, G., Manuello, A., and Mazza, L., Optimization of the Cross Section of an Elastomeric Seal for Pneumatic Cylinders, Journal of Tribology, 128, pp. 406-413, 2006.

[3] Lee, K. O., Hur, Y. M., Kang, J. H., and Kang, S. S., Performance Estimation of Dust Wipers for Hydraulic Cylinders and Optimization of Geometric Design Variables, Journal of Materials Processing Technology, 187-188, pp. 215-219, 2007.

[4] Martínez, L., Álvarez, L., Huttel, Y., Méndez, J., Román, E., Vanhulsel, A., Verheyde, B., Jacobs, R., Surface analysis of NBR and HNBR elastomers modified with different plasma treatments, 6th Iberian Vacuum Meeting IVM-6, 26-28 June 2006, Salamanca, Spain.

[5] Kligerman, Y., Etsion, and I., Shinkarenko, A., Improving Tribological Performance of Piston Rings by Partial Surface Texturing, Journal of Tribology, 127 (3), pp. 632-638, 2005.

[6] Hermann, A., Dabisch, T., Influence on tribological behaviour of pneumatic actuators due to modifications of polymer compounds, Proceedings of the 15th International Sealing Conference, Stuttgart, Germany, 7-8 October, pp. 265-280, 2008.

[7] Pei, Y.T., Bui, X.L., Zhou, X.B., De Hosson J.Th.M., Tribological behavior of W-DLC coated rubber seals, Surface and Coating Technology, 202, pp1869-1875, 2008.

[8] Verheyde, B., Havermans, D., Vanhulsel A., Characterization and Tribological Behaviour of Siloxane-based Plasma Coatings on HNBR Rubber, Plasma Processes and Polymers, 8, pp.755-762, 2011.

[9] Bignardi, C., Manuello, A., and Mazza, L., Photoelastic Measurements and Computation of the Stress Field and Contact Pressure in a Pneumatic Lip Seal, Tribology International, 32 (1), pp. 1-13, 1999.

[10] Belforte, G., Conte, M., Manuello, A., Mazza, L., and Visconte, C. (2009), Experimental and Numerical Evaluation of Contact Pressure in Pneumatic Seals, Tribology International, 42 (1), pp 169-175.

[11] Lee, C. Y., Lin, C. S., Jian, R. Q., and Wen, C. Y., Simulation and Experimentation of the Contact Width and Pressure Distribution of Lip Seals, Tribology International, 39, pp. 915-920, 2006.

[12] Prokop, H. J., Muller, H.K., Film thickness, contact pressure and friction of PTFE rod seals. Proceedings of the 12th International Conference on Fluid Sealing, Brighton, UK, pp.147-163, 1989.

[13] Horl, L., Haas, W., Nisler, U. A comparison of test methods for hydraulic rod seals. Sealing Tech., 12, 8-13, 2009. 
[14] Wangenheim, M., Kozma, M., Mate, L., Gronefeld, P., Friction behaviour of grease lubricated seals, Proceedings of the 15th International Sealing Conference, Stuttgart, Germany, 7-8 October, pp. 265-280, 2008.

[15] G. Belforte, A. Manuello, S. Liu, L. Mazza, Wear and failure analysis in pneumatic cylinders under radial load, Proc. of the 11th Int. Sealing Conference., Dresden, Germany, pp. 317-330, 1999.

[16] J. Chen, J.G. Ma, and Q. Wu, Fault mechanism analysis and accelerate life testing for pneumatic cylinders, Proceedings - IEEE INDIN 2008: 6th IEEE International Conference on Industrial Informatics, pp1694-1699, 2008.

[17] Belforte, G., D’Alfio, N., and Raparelli, T., Experimental Analysis of Friction Forces in Pneumatic Cylinders, Journal of Fluid Control, 78, pp. 42-60, 1989.

[18] Raparelli, T., Manuello, A., and Mazza, L., Experimental and Numerical Study of Friction in Elastomeric Seal for Pneumatic Cylinders, Tribology International, 30 (7), pp 547-552, 1997.

[19] Belforte G., Romiti A., Raparelli T., Study and realization of high efficiency sealless cylinder, International Fluid Power Conference '92, 2426 March 1992, Chicago, USA, pp 29-35, 1992.

[20] Belforte, G., Raparelli, T., Mazza, L., Trivella, A., Analysis, design and comparison of different types of pistons for sealless pneumatic cylinders and valves. Tribology Transactions, 48, pp 377-388, 2005.

[21] Belforte G., Ferraresi C., Raparelli T., A new low-friction pneumatic actuator, 2nd Int. Symp. on Fluid Power, Transmission and Control ISFP '95, Shanghai, P.R. CHINA, 5/7-10-95, 1995.

[22] Visconte, C., Conte, M., and Mattone, M. C., Analysis of the Leakage Path in an Air-Lubricated Seal, Tribology International, 42 (6), pp 844-848, 2009. 